\title{
High-dose influenza vaccination and mortality among predominantly male, white, senior veterans, United States, 2012/13 to 2014/15
}

Yinong Young-Xu' $\mathbf{u}^{1,2}$, Julia Thornton Snider ${ }^{3}$, Salaheddin M Mahmud ${ }^{4,5}$, Ellyn M Russo ${ }^{1}$, Robertus Van Aalst ${ }^{6,7}$, Edward W

Thommes 6,8 , Jason KH Lee ${ }^{9,10}$, Ayman Chit ${ }^{6,9}$

1. Clinical Epidemiology Program, Veterans Affairs Medical Center, White River Junction, United States

2. Department of Psychiatry, Geisel School of Medicine at Dartmouth, Hanover, United States

3. Precision Health Economics, Oakland, United States

4. Department of Community Health Sciences, College of Medicine, University of Manitoba, Winnipeg, Canada

5. George and Fay Yee Center for Healthcare Innovation, University of Manitoba/Winnipeg Regional Health Authority, Winnipeg, Canada

6. Sanofi Pasteur, Swiftwater, United States

7. Faculty of Medical Sciences, University of Groningen, Groningen, the Netherlands

8. Department of Mathematics and Statistics, University of Guelph, Guelph, Canada

9. Leslie Dan School of Pharmacy, University of Toronto, Toronto, Canada

10. Sanofi Pasteur, Toronto, Canada

Correspondence: Yinong Young-Xu (Yinong.Young-Xu@va.gov)

Citation style for this article:

Young-Xu Yinong, Thornton Snider Julia, Mahmud Salaheddin M, Russo Ellyn M, Van Aalst Robertus, Thommes Edward W, Lee Jason KH, Chit Ayman . High-dose influenza vaccination and mortality among predominantly male, white, senior veterans, United States, 2012/13 to 2014/15. Euro Surveill. 2020;25(19):pii=1900401. https://doi.org/10.2807/1560-7917.ES.2020.25.19.1900401

Introduction: It is unclear whether high-dose influenza vaccine (HD) is more effective at reducing mortality among seniors. Aim: This study aimed to evaluate the relative vaccine effectiveness (rVE) of HD. Methods: We linked electronic medical record databases in the Veterans Health Administration (VHA) and Medicare administrative files to examine the rVE of HD vs standard-dose influenza vaccines (SD) in preventing influenza/pneumonia-associated and cardiorespiratory mortality among VHA-enrolled veterans 65 years or older during the 2012/13, 2013/14 and 2014/15 influenza seasons. A multivariable Cox proportional hazards model was performed on matched recipients of $H D$ vs SD, based on vaccination time, location, age, sex, ethnicity and VHA priority level. Results: Among 569,552 person-seasons of observation, 207,574 (36\%) were HD recipients and 361,978 (64\%) were SD recipients, predominantly male (99\%) and white (82\%). Pooling findings from all three seasons, the adjusted rVE estimate of HD vs SD during the high influenza periods was $42 \%$ (95\% confidence interval (CI): 24-59) against influenza/pneumonia-associated mortality and $27 \%(95 \% \mathrm{Cl}: 23-32)$ against cardiorespiratory mortality. Residual confounding was evident in both early and late influenza periods despite matching and multivariable adjustment. Excluding individuals with high 1-year predicted mortality at baseline reduced the residual confounding and yielded rVE of $36 \%(95 \%$ $\mathrm{Cl}: 10-62)$ and $25 \%(95 \% \mathrm{Cl}: 12-38)$ against influenza/pneumonia-associated and cardiorespiratory mortality, respectively. These were confirmed by results from two-stage residual inclusion estimations. Discussion: The HD was associated with a lower risk of influenza/pneumonia-associated and cardiorespiratory death in men during the high influenza period.

\section{Introduction}

Seasonal influenza epidemics result in substantial health burden. Among the 9 million veterans under the care of the United States (US) Veterans Health Administration (VHA), nearly 3,800 are estimated to die annually from respiratory and circulatory complications associated with seasonal influenza infections [1-4]. The clinical risk for hospitalisation and death is highest among persons aged 65 years or older (hereinafter referred to as seniors) because of frailty and immunosenescence [5,6]. In 2009, the US Food and Drug Administration licensed an injectable high-dose inactivated trivalent influenza vaccine (HD) (Fluzone High-Dose, Sanofi Pasteur, Swiftwater, US). The HD contains four times more influenza haemagglutinin antigen than standard-dose influenza vaccines (SD) (6o $\mu \mathrm{g}$ vs $15 \mu \mathrm{g}$ per strain) and is designed to provide improved protection in seniors.

Beginning with the $2010 / 11$ season, the VHA began to introduce the HD across its medical centres, largely relying on individual facilities to decide the volume to order and on physicians to decide the recipients of the specific type of vaccine. While the majority of VHA senior patients still receive SD, the proportion of $H D$ 
Schematic overview of influenza season and study periods, United States, 2012/13-2014/15

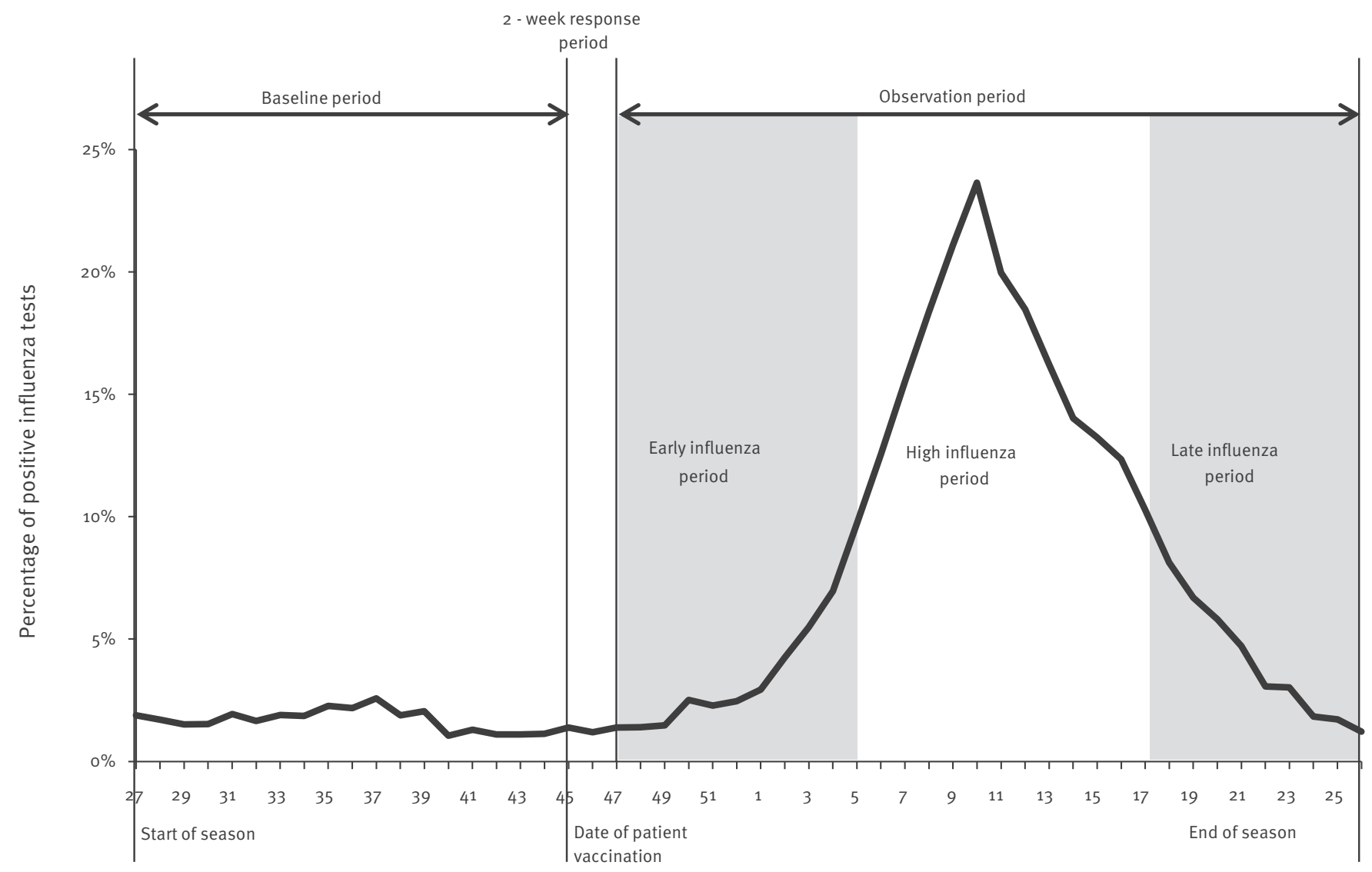

Week

recipients has been steadily rising, from $3 \%$ during $2010 / 11$ to ca $11 \%$ during $2014 / 15$ (data not shown). Senior VHA patients can also obtain influenza vaccination using non-VHA insurance coverage, such as that provided by Centers for Medicare and Medicaid Services (Medicare), once they become eligible.

Clinical trials have shown that HD was 7\% (95\% confidence interval $(\mathrm{Cl}): 0.5-12.8)$ and $8 \%(95 \% \mathrm{Cl}: 0.3-14)$ more effective than SD in preventing all-cause hospital admissions in ambulatory and nursing home seniors, respectively $[7,8]$. The advantage of $H D$ in preventing hospitalisations has also been confirmed by several observational studies [9-13]. However, it is unclear whether HD is more effective at reducing mortality among seniors, especially given the ongoing debate surrounding the scale of mortality attributable to influenza and the effectiveness of influenza vaccines among the elderly. Although a number of HD studies have reported mortality outcomes [7-10], only one study has investigated this question as a primary objective: Shay et al. found that HD vaccination was $24 \%$ (95\% Cl: 6-42) more effective in preventing mortality after influenza hospital admission [12]. Nevertheless, potential confounding because of indication associated with 'frailty' bias remains to be examined and mitigated $[14,15]$. We examined the relative vaccine effectiveness (rVE) of HD compared with SD against mortality outcomes among VHA veterans during the 2012/13, 2013/14 and 2014/15 influenza seasons.

\section{Methods}

\section{Design and data sources}

The VHA is the single largest integrated healthcare system in the US and provides clinical care to more than 9 million military veterans at more than 170 medical centres and ca 1,400 community-based outpatient clinics. We obtained de-identified VHA electronic medical records (EMR) data and administrative health records for VHA enrolees from Medicare fee-for-service files. These records supplement the VHA database as many VHA patients seek healthcare outside the VHA system once they turn 65 and qualify for such additional benefits. We obtained vital status from the VHA vital status files and death certificate data from the National Death Index (NDI) through the Centre of Excellence for Suicide Prevention Joint Department of Veterans Affairs and Department of Defence Suicide Data Repository NDI (extracted: 22 January 2019) [16].

Using these data sources, a retrospective cohort study was conducted to compare the risk of mortality among HD and SD recipients for the 2012/13, 2013/14 and 
2014/15 seasons. Two causes of death were examined: (i) influenza- or pneumonia-associated and (ii) cardiorespiratory, as these were likely to be impacted by influenza vaccination [10]. Causes of death were classified using the International Classification of Diseases, 10th revision (ICD-10) [17].

\section{Ethical statement}

This study was approved by the Veteran's Institutional Review Board of Northern New England at the White River Junction VHA Medical Center (No. 903343). All study procedures were carried out in compliance with federal and institutional ethical guidelines. The requirement to obtain informed consent from study participants was waived as there was no more than a minimal risk to the privacy of individuals.

\section{Study population and influenza vaccination}

The study population included all VHA enrolees who turned 66 years or older by 1 July for each of the influenza seasons and maintained their enrolment until the end of the season (30 June of the following year) or until death, whichever occurred earlier. Influenza vaccination was identified using current procedural terminology (CPT) codes (SD CPT codes: 90655-90659 and Q2034-Q2039; HD CPT code: 90662). We included veterans who received either an HD or SD and excluded any who did not have a record of vaccination or received more than one influenza vaccine in the same season to ensure valid comparison.

\section{Influenza activity periods}

For each Centers for Disease Control and Prevention (CDC) multi-state reporting region [18], we divided each season into three periods of potential influenza activity, following methods employed in previous research [19]. We used weekly reports of the percentage of positive influenza tests among all influenza tests performed in each region to define (i) high influenza period as the time between the first and last occurrences of 2 consecutive weeks with at least 10\% influenza positivity, (ii) early influenza period as the time from 1 September to the start of the high influenza period and (iii) late influenza period as time from the end of the high influenza period to the end of June (Figure 1).

\section{Baseline characteristics}

For each study subject, the baseline period began at the end of each previous season in week 27 (beginning of July) and ended at his/her influenza vaccination date. Characteristics measured during the baseline period included demographics, comorbidities, and healthcare utilisation. Demographics comprised age, sex, ethnicity, geographic region and priority rating of VHA care (as a proxy for socioeconomic status because it is partially based on income and the capacity for gainful employment) [20].

Comorbidities were defined according to an adaptation of Deyo-Charlson comorbidity score [21] using diagnosis codes captured during hospital and ambulatory visits. As a proxy measure for frailty, we used the care assessment need (CAN) score developed specifically to predict hospitalisation within 1 year among VHA patients. In addition to incorporating the medical conditions used in the Charlson and Elixhauser scores [22], CAN includes sociodemographic characteristics, the prior year's levels of healthcare utilisation (e.g. number of primary care, non-emergency department outpatient visits), medication use and laboratory test results [23]. We used the maximum CAN score in the 4 weeks before vaccination. Healthcare utilisation was measured as the number of all-cause hospitalisations.

\section{Matching}

Each $H D$ recipient was matched to at least one, and at most two, residents of the same VHA facility who received an SD within the same week. This process addressed temporal and geographical factors possibly associated with access to HD and influenza exposure (i.e. influenza outbreak activity). In addition, these HD and SD recipients were matched on all demographic variables including age group $(65-74,75-84$ and $\geq 85$ years), sex, ethnicity (white vs other) and VHA priority rating (high vs low). All analyses were performed on the matched populations.

\section{Statistical analysis}

We used standardised mean difference (SMD) as a measure of statistical differences between two groups. SMD was calculated by dividing the difference in mean outcome between groups by the pooled standard deviation of the two groups. The absolute value of this division is then multiplied by 100 , with a value greater than 10 denoting statistical significance [24]. Cox proportional hazards modelling was used to estimate the hazard ratios (HR) and $95 \% \mathrm{Cl}$ for the association between receipt of the $\mathrm{HD}$ and mortality separately for each outcome and influenza activity period. Within each influenza period, follow-up time began on the index date, defined as 2 weeks following vaccination, or the beginning of each influenza period, whichever came last. This was done because in primed healthy adults, the peak serum antibody levels are typically observed 2 weeks post-vaccination [25]. We excluded study subjects who received vaccination within 15 days of the end of each influenza period to allow for at least 1 day of follow-up. The observation period ended on the date of disenrollment from either VHA or Medicare, end of each of the three influenza season periods or date of death, whichever occurred first. For example, if a patient was vaccinated on 1 October, then his/her follow-up time for the early influenza period began on 15 October. If he/she died from an influenza/pneumonia-associated cause on 1 December, his/her follow-up time would end then, regardless of whether the high influenza period in his/her region had begun. The models adjusted for all baseline comorbidities and healthcare utilisation and adjusted for demographics through matching. 
TABLE 1

Baseline characteristics after matching by standard dose vs high-dose influenza vaccination among predominantly male, white, senior veterans, United States, 2012/13-2014/15 $(\mathrm{n}=569,552)$

\begin{tabular}{|c|c|c|c|c|c|c|c|c|c|c|}
\hline \multirow{2}{*}{\multicolumn{2}{|c|}{$\begin{array}{l}\text { Season } \\
\text { Influenza vaccine }\end{array}$}} & \multicolumn{3}{|c|}{$2012 / 13$} & \multicolumn{3}{|c|}{$2013 / 14$} & \multicolumn{3}{|c|}{$2014 / 15$} \\
\hline & & \multirow{2}{*}{$\frac{\text { SD }}{89,700}$} & \multirow{2}{*}{$\frac{H D}{49,950}$} & \multirow{2}{*}{$\mathrm{SMD}^{\mathrm{a}}$} & \multirow{2}{*}{$\frac{\text { SD }}{117,518}$} & \multirow{2}{*}{$\frac{H D}{65,267}$} & \multirow{2}{*}{$\mathrm{SMD}^{\mathrm{a}}$} & \multirow{2}{*}{$\frac{\text { SD }}{154,760}$} & \multirow{2}{*}{$\begin{array}{c}\text { HD } \\
92,357\end{array}$} & \multirow{2}{*}{$\mathrm{SMD}^{\mathrm{a}}$} \\
\hline Study popul & & & & & & & & & & \\
\hline \multirow{2}{*}{ Sex } & Female & $1 \%$ & $1 \%$ & 1 & $1 \%$ & $1 \%$ & 1 & $1 \%$ & $1 \%$ & 1 \\
\hline & Male & $99 \%$ & $99 \%$ & 0 & $99 \%$ & $99 \%$ & 1 & $99 \%$ & $99 \%$ & 1 \\
\hline \multirow{5}{*}{ Ethnicity } & White & $80 \%$ & $79 \%$ & 3 & $82 \%$ & $81 \%$ & 2 & $83 \%$ & $83 \%$ & 2 \\
\hline & African-American & $8 \%$ & $10 \%$ & 4 & $8 \%$ & $7 \%$ & 3 & $8 \%$ & $7 \%$ & 3 \\
\hline & Hispanic & $8 \%$ & $8 \%$ & 1 & $7 \%$ & $8 \%$ & 6 & $6 \%$ & $7 \%$ & 5 \\
\hline & Other & $2 \%$ & $2 \%$ & 1 & $2 \%$ & $2 \%$ & 1 & $2 \%$ & $2 \%$ & 1 \\
\hline & Unknown & $1 \%$ & $1 \%$ & 0 & $1 \%$ & $1 \%$ & 0 & $1 \%$ & $1 \%$ & 0 \\
\hline \multirow{3}{*}{$\begin{array}{l}\text { Age group } \\
\text { (years) }\end{array}$} & $65-74$ & $37 \%$ & $38 \%$ & 2 & $40 \%$ & $41 \%$ & 2 & $44 \%$ & $45 \%$ & 1 \\
\hline & $75-84$ & $43 \%$ & $42 \%$ & 2 & $40 \%$ & $40 \%$ & 1 & $37 \%$ & $37 \%$ & 1 \\
\hline & $\geq 85$ & $20 \%$ & $20 \%$ & 1 & $20 \%$ & $19 \%$ & 1 & $19 \%$ & $19 \%$ & 1 \\
\hline \multirow{2}{*}{ Priority } & High priority & $38 \%$ & $39 \%$ & 1 & $40 \%$ & $40 \%$ & 0 & $42 \%$ & $42 \%$ & 1 \\
\hline & Low priority & $62 \%$ & $61 \%$ & 1 & $60 \%$ & $60 \%$ & 0 & $58 \%$ & $58 \%$ & 1 \\
\hline \multirow{10}{*}{ HHS region } & 1 & $5 \%$ & $4 \%$ & 2 & $6 \%$ & $5 \%$ & 1 & $8 \%$ & $7 \%$ & 2 \\
\hline & 2 & $9 \%$ & $9 \%$ & 2 & $9 \%$ & $9 \%$ & 1 & $12 \%$ & $11 \%$ & 2 \\
\hline & 3 & $11 \%$ & $11 \%$ & 2 & $11 \%$ & $11 \%$ & 1 & $11 \%$ & $13 \%$ & 6 \\
\hline & 4 & $28 \%$ & $28 \%$ & 0 & $30 \%$ & $30 \%$ & 1 & $28 \%$ & $27 \%$ & 2 \\
\hline & 5 & $14 \%$ & $11 \%$ & 8 & $12 \%$ & $10 \%$ & 5 & $11 \%$ & $10 \%$ & 5 \\
\hline & 6 & $9 \%$ & $11 \%$ & 4 & $9 \%$ & $10 \%$ & 1 & $7 \%$ & $7 \%$ & 0 \\
\hline & 7 & $11 \%$ & $14 \%$ & 9 & $9 \%$ & $12 \%$ & 9 & $8 \%$ & $10 \%$ & 8 \\
\hline & 8 & $3 \%$ & $3 \%$ & 1 & $3 \%$ & $3 \%$ & 1 & $4 \%$ & $3 \%$ & 2 \\
\hline & 9 & $7 \%$ & $7 \%$ & 2 & $9 \%$ & $8 \%$ & 1 & $10 \%$ & $10 \%$ & 0 \\
\hline & 10 & $3 \%$ & $3 \%$ & 0 & $2 \%$ & $2 \%$ & 1 & $2 \%$ & $2 \%$ & 2 \\
\hline \multirow{17}{*}{ Morbidity } & Malignancy & $16 \%$ & $18 \%$ & 5 & $16 \%$ & $18 \%$ & 7 & $16 \%$ & $18 \%$ & 6 \\
\hline & Metastatic solid tumour & $1 \%$ & $1 \%$ & 0 & $1 \%$ & $1 \%$ & 0 & $1 \%$ & $1 \%$ & 1 \\
\hline & Congestive heart failure & $12 \%$ & $12 \%$ & 2 & $11 \%$ & $12 \%$ & 2 & $11 \%$ & $12 \%$ & 1 \\
\hline & Chronic pulmonary disease & $19 \%$ & $20 \%$ & 3 & $19 \%$ & $20 \%$ & 5 & $19 \%$ & $20 \%$ & 2 \\
\hline & Cerebrovascular disease & $10 \%$ & $11 \%$ & 3 & $9 \%$ & $10 \%$ & 3 & $9 \%$ & $10 \%$ & 3 \\
\hline & Dementia & $2 \%$ & $2 \%$ & 0 & $2 \%$ & $2 \%$ & 1 & $2 \%$ & $2 \%$ & 0 \\
\hline & Diabetes with complications & $10 \%$ & $11 \%$ & 3 & $10 \%$ & $11 \%$ & 3 & $11 \%$ & $12 \%$ & 3 \\
\hline & $\begin{array}{l}\text { Diabetes without chronic } \\
\text { complications }\end{array}$ & $39 \%$ & $39 \%$ & 1 & $39 \%$ & $39 \%$ & 1 & $39 \%$ & $39 \%$ & 0 \\
\hline & HIV/AIDS & $0.2 \%$ & $0.2 \%$ & 1 & $0.2 \%$ & $0.2 \%$ & 0 & $0 \%$ & $0 \%$ & 1 \\
\hline & Mild liver disease & $1 \%$ & $1 \%$ & 0 & $2 \%$ & $2 \%$ & 0 & $2 \%$ & $2 \%$ & 1 \\
\hline & Moderate/severe liver disease & $0.2 \%$ & $0.2 \%$ & 0 & $0.2 \%$ & $0.2 \%$ & 1 & $0 \%$ & $0 \%$ & 0 \\
\hline & Myocardial infarction & $3 \%$ & $3 \%$ & 0 & $3 \%$ & $3 \%$ & 2 & $3 \%$ & $3 \%$ & 1 \\
\hline & Hemiplegia/paraplegia & $1 \%$ & $1 \%$ & 0 & $1 \%$ & $1 \%$ & 1 & $1 \%$ & $1 \%$ & 1 \\
\hline & Peptic ulcer disease & $1 \%$ & $1 \%$ & 1 & $1 \%$ & $1 \%$ & 1 & $1 \%$ & $1 \%$ & 1 \\
\hline & Peripheral vascular disease & $13 \%$ & $14 \%$ & 4 & $12 \%$ & $14 \%$ & 5 & $12 \%$ & $14 \%$ & 6 \\
\hline & Rheumatoid disease & $2 \%$ & $2 \%$ & 2 & $2 \%$ & $2 \%$ & 2 & $2 \%$ & $2 \%$ & 2 \\
\hline & Renal disease & $13 \%$ & $13 \%$ & 0 & $13 \%$ & $13 \%$ & 2 & $13 \%$ & $13 \%$ & 1 \\
\hline \multirow{3}{*}{$\begin{array}{l}\text { Continuous } \\
\text { variables }^{\text {b }}\end{array}$} & Age & $74 \cdot 5$ & 74.9 & 5 & 76.9 & 77.1 & 1 & 76.6 & 76.7 & 2 \\
\hline & Number of hospitalisations & 0.19 & 0.18 & 2 & 0.13 & 0.11 & 3 & 0.14 & 0.12 & 5 \\
\hline & $\begin{array}{l}\text { VHA care assessment need } \\
\text { score }\end{array}$ & 0.05 & 0.04 & 3 & 0.054 & 0.047 & 9 & 0.05 & 0.04 & 9 \\
\hline
\end{tabular}

HD: high-dose influenza vaccine; HHS: Health and Human Services; VHA: Veterans Health Administration; SD: standard-dose influenza vaccine; SMD: standardised mean difference.

a An SMD less than 10 in absolute value suggests no important difference between the two cohorts [24].

b Continuous variables reported as mean. 
Hazard ratios pooled over three influenza seasons and number of deaths by cause and influenza period, among predominantly male, white, senior veterans, United States, 2012/13-2014/15 ( $\mathrm{n}=569,552)$

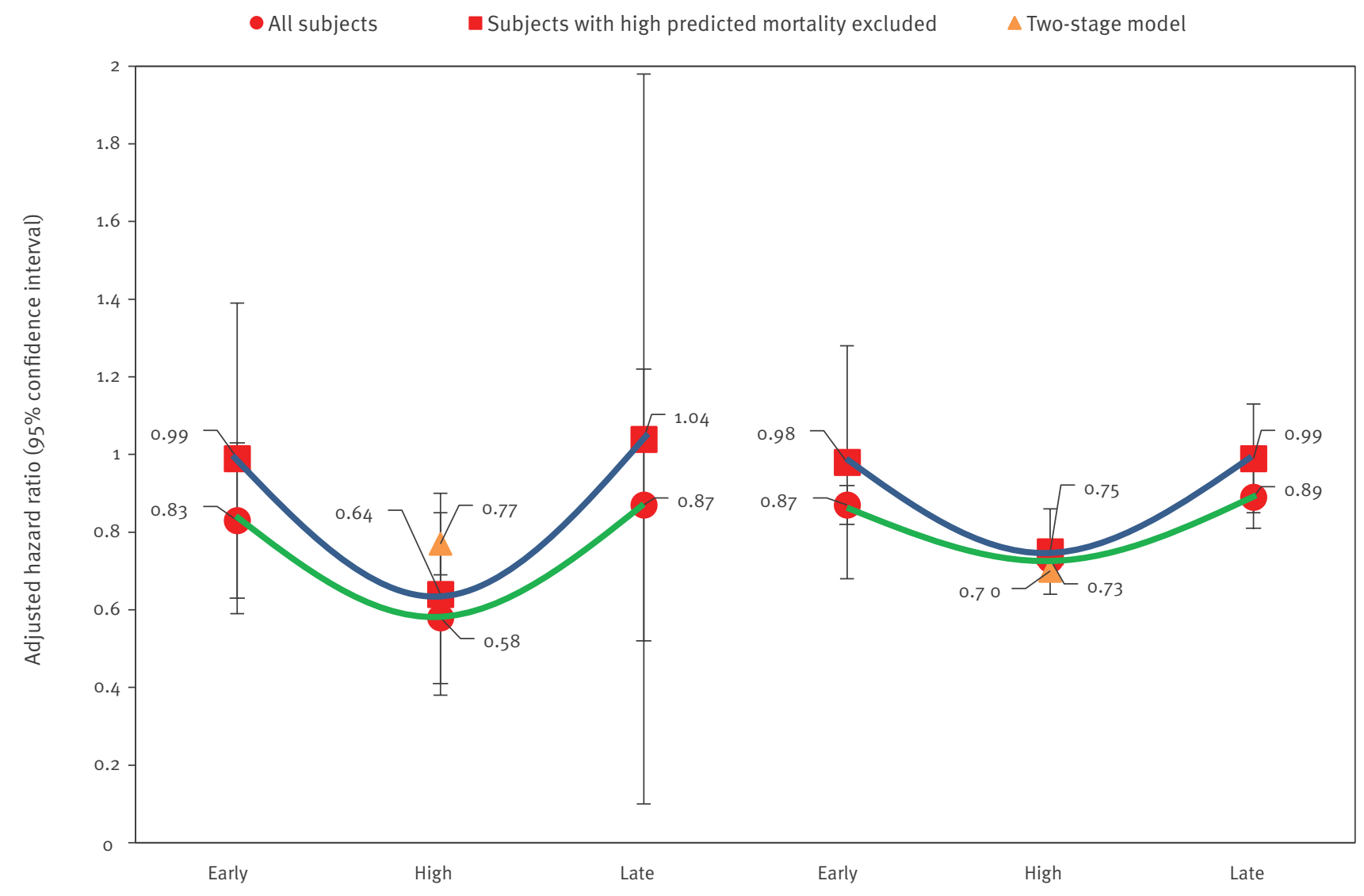

\begin{tabular}{|c|c|c|c|c|c|c|}
\hline \multirow{2}{*}{ Season } & \multicolumn{3}{|c|}{ Influenza/pneumonia } & \multicolumn{3}{|c|}{ Cardiorespiratory } \\
\hline & \multicolumn{6}{|c|}{ Number of deaths } \\
\hline $2012 / 13$ & 13 & 90 & 24 & 249 & 1,761 & 705 \\
\hline $2013 / 14$ & 12 & 101 & 32 & 383 & 2,149 & 847 \\
\hline $2014 / 15$ & 21 & 165 & 64 & 435 & 2,976 & 1,401 \\
\hline Total & 46 & 356 & 120 & 1,067 & 6,886 & 2,953 \\
\hline
\end{tabular}

We also conducted analyses with mortality as a binary outcome. This was achieved using a two-stage residual inclusion model, also known as control functions approach [26], to account for potential confounding from measured and unmeasured variables. The rVE was calculated as $(1-H R) \times 100 \%$. All tests were twotailed, and 0.05 was the level of statistical significance. We performed statistical analyses using Stata 15 (StataCorp, College Station, TX).

To further quantify the presence of confounding by indication due to frailty, we used a logistic regression model to predict mortality for all cohort members during each influenza season. We then re-ran the fully adjusted Cox proportional hazard model on the subpopulation that excluded individuals at higher levels of illness severity, as measured by predicted oneyear mortality [19]. We estimated rVE for each season separately, and then pooled the results after statistically examining heterogeneity caused by inter-season variability.

\section{Results}

We included 569,552 person-seasons of observation where 207,574 (36\%) were among HD recipients and 361,978 (64\%) were among SD recipients during the three seasons; $99 \%$ were male and $80 \%$ were of nonHispanic white origin (Table 1). We matched 49,950, 65,267 and $92,357 \mathrm{HD}$ recipients to $89,700,117,518$ and 154,760 SD recipients for the $2012 / 13,2013 / 14$ and $2014 / 15$ season, respectively. Matched HD or SD recipients were similar with respect to baseline covariates as well as CAN score. For the matched cohorts, we observed 127, 145 and 250 influenza/pneumonia-associated deaths and 2,715, 3,379 and 4,812 cardiorespiratory deaths for the 2012/13, 2013/14 and 2014/15 season, respectively (Figure 2 ).

During the high influenza periods, rVE $((1-\mathrm{HR}) \times 100 \%)$ for influenza/pneumonia-associated mortality was $23 \%$ (95\% Cl: -83 to 67 ), $32 \%$ (95\% Cl: -17 to 60 ) and $47 \%$ (95\% Cl: 21-65) for seasons 2012/13, 2013/14 and $2014 / 15$, respectively, with a pooled rVE of $42 \%(95 \%$ 
Cl: 24-59), presented in Table 2. For cardiorespiratory deaths, the rVE were 23\% (95\% Cl: 13-32), 28\% (95\% $\mathrm{Cl}: 19-35)$, and $30 \%(95 \% \mathrm{Cl}: 23-36)$ for the three study seasons, respectively, with a pooled rVE of $27 \%$ (95\% Cl: 23-32).

During the early influenza periods, rVE (1-HR) for influenza/pneumonia-associated mortality was 0\% (95\% Cl: -56 to 32 ), $10 \%$ ( $95 \% \mathrm{Cl}:-88$ to 57$)$ and $23 \%(95 \%$ Cl: -5 to 43) for seasons 2012/13, 2013/14 and 2014/15, respectively, with a pooled $\mathrm{rVE}$ of $17 \%(95 \% \mathrm{Cl}:-3$ to 37). For cardiorespiratory deaths, rVE was $5 \%(95 \% \mathrm{Cl}$ : -41 to 37$), 7 \%(95 \% \mathrm{Cl}:-8$ to 20$)$ and $14 \%(95 \% \mathrm{Cl}$ : 8-20) for the three study seasons, respectively, with a pooled rVE of $13 \%$ ( $95 \% \mathrm{Cl}: 7-18)$.

During the late influenza periods, rVE (1-HR) for influenza/pneumonia-associated mortality was $4 \%(95 \%$ Cl: -143 to 62 ), $13 \%$ (95\% Cl: $-86 \%$ to $59 \%$ ) and $16 \%$ (95\% Cl: -46 to 52 ) for seasons 2012/13, 2013/14 and $2014 / 15$, respectively, with a pooled rVE of $13 \%$ (95\% $\mathrm{Cl}:-22$ to 48$)$. For cardiorespiratory deaths, rVE was $3 \%$ (95\% Cl: -39 to 32 ), $9 \%(95 \% \mathrm{Cl}:-5$ to 22 ) and $13 \%$ (95\% Cl: 2-22) for the three study seasons, respectively, with a pooled rVE of $11 \%$ ( $95 \% \mathrm{Cl}: 3-19)$.

One-year mortality was accurately predicted (C-statistic $=0.84)$ using a logistic regression model. Excluding individuals with greater than $5 \%$ predicted mortality (ca $21 \%$ of the cohort) had a considerable impact on the HR estimates (Figure 2). During the early influenza periods, pooled rVE for influenza/pneumoniaassociated mortality was $1 \%(95 \% \mathrm{Cl}:-44$ to 46$)$ and $2 \%(95 \% \mathrm{Cl}:-28$ to 32$)$ for cardiorespiratory deaths, noticeably closer to no effect (i.e. $r V E=0 \%$ ) compared with the analysis including all cohort members (Table 2). The estimates for the late influenza periods also moved closer to the null when individuals at high predicted probabilities of mortality were excluded; pooled rVE were $-4 \%(95 \% \mathrm{Cl}:-98$ to 89$)$ and $1 \%(95 \% \mathrm{Cl}:-12$ to 15) for influenza/pneumonia-associated and cardiorespiratory mortality, respectively. Excluding individuals with high 1-year predicted mortality at baseline reduced the residual confounding and yielded rVE of $36 \%(95 \% \mathrm{Cl}: 10-62)$ and $25 \%(95 \% \mathrm{Cl}: 12-38)$ against influenza/pneumonia-associated mortality and cardiorespiratory mortality, respectively, during the high influenza period.

Confounding by indication was further studied with a two-stage residual inclusion model. Pooling findings from all three seasons, the adjusted rVE estimate of HD vs SD during the high influenza periods was $23 \%$ (95\% Cl: 17-28) against influenza/pneumonia-associated mortality and 30\% (95\% Cl: 23-38) against cardiorespiratory mortality (Table 3 ). The estimates differed by season, but with overlapping $\mathrm{Cl}$. This was more evident for influenza/pneumonia-associated mortality: the rVE was 29\% (95\% Cl: 21-36), $11 \%$ (95\% Cl: -1 to 22 ) and $21 \%(95 \% \mathrm{Cl}: 11-30)$ for the three seasons, respectively. Finally, we estimated adjusted rVE during the baseline (summer) period against all-cause hospitalisations to assess confounding by indication. The rVE during the baseline period were close to the null: $-7 \%(95 \% \mathrm{Cl}:-21-5),-6 \%(95 \% \mathrm{Cl}:-11$ to -2$)$ and $5 \%$ (95\% Cl: 2-8) for the three seasons, respectively, for a pooled estimate of $-1 \%(95 \% \mathrm{Cl}:-5-2)$ (Table 3$)$.

\section{Discussion}

In our analysis of the 2012/13, 2013/14 and 2014/15 influenza seasons, we found receiving HD among a population of predominantly male, white, senior veterans to be associated with an additional reduction in mortality as compared with receiving SD. Although only a portion of all winter deaths can be attributed to influenza [27], the additional $36 \%$ (95\% Cl: 10-62) reduction in influenza/pneumonia-associated mortality and $25 \%$ (95\% Cl: $12-38)$ reduction in cardiorespiratory mortality for HD vs SD present substantial impact as nearly 3,800 VHA patients die annually from respiratory and circulatory complications associated with seasonal influenza infections [1].

An HR of 1 implies a null effect (i.e. no difference in vaccine effectiveness). Thus, we expected to see HR furthest from the null, indicating largest relative vaccine effect, for the periods when influenza is in high circulation and more likely to trigger the largest proportion of deaths. For all seasons, and for both influenza/pneumonia-associated and cardiorespiratory mortality, we observed the same pattern: The HR were the furthest from the null during the high influenza period, while $\mathrm{HR}$ were much closer to the null during the early and late influenza periods. This created a U-shape pattern, suggesting statistically significant rVE during the high activity periods. During the early and late influenza periods, most rVE estimates associated with either cardiorespiratory or influenza/pneumonia-associated mortality displayed evidence of differential impact outside the high activity periods, albeit smaller. For example, the rVE for cardiorespiratory mortality were both statistically significant for the $2014 / 15$ season, $14 \%$ (95\% Cl: $8-20)$ in the early period and $13 \%(95 \% \mathrm{Cl}: 2-22)$ in the late period, if not controlled for residual confounding. During the early and late influenza periods, when influenza viruses were not circulating or circulating at a low level, these significant rVE could indicate the presence of residual confounding after matching and multivariable survival analysis. The appearance and confirmation of residual confounding during these periods are not new. Campitelli et al., among others, have found similar bias in their study of influenza vaccines' impact on mortality [19]. However, this bias cannot explain away all the observed mortality benefit associated with HD during the high influenza periods, as the magnitudes of the rVE for the early and late influenza periods were half to one third of the rVE during the high influenza period. Furthermore, excluding individuals with high 1-year predicted mortality at baseline resulted in rVE much closer to the null, indicating reduced levels of residual confounding. Receipt of SD was more prevalent than HD among veterans with high 1-year predicted 
Relative vaccine effectiveness of high-dose vs standard dose influenza vaccination and mortality by influenza period, matched and adjusted using Cox proportional hazards model, among predominantly male, white, senior veterans, United States, 2012/13-2014/15 $(\mathrm{n}=569,552)$

\begin{tabular}{|c|c|c|c|c|c|c|c|}
\hline \multirow{4}{*}{ Population } & \multirow{4}{*}{ Season } & Influenza/p & monia cause & of death & Cardiores & oiratory caus & of death \\
\hline & & \multicolumn{6}{|c|}{ Influenza period } \\
\hline & & Early & High & Late & Early & High & Late \\
\hline & & \multicolumn{3}{|c|}{ IVE $\%(95 \% \mathrm{Cl})$} & \multicolumn{3}{|c|}{ rVE \% (95\% Cl) } \\
\hline \multirow{4}{*}{ All subjects } & $2012 / 13$ & $\begin{array}{c}0 \\
(-56-36)\end{array}$ & $\begin{array}{c}23 \\
(-83 \text { to } 67)\end{array}$ & $\begin{array}{c}4 \\
(-143 \text { to } \\
62)\end{array}$ & $\begin{array}{c}5 \\
(-41 \text { to } 37)\end{array}$ & $\begin{array}{c}23 \\
\text { (13 to } 32)\end{array}$ & $\begin{array}{c}3 \\
(-39 \text { to } 32) \\
\end{array}$ \\
\hline & $2013 / 14$ & $\begin{array}{c}10 \\
(-88 \text { to } 57) \\
\end{array}$ & $\begin{array}{c}32 \\
(-17 \text { to } 60) \\
\end{array}$ & $\begin{array}{c}13 \\
(-86 \text { to } 59) \\
\end{array}$ & $\begin{array}{c}7 \\
(-8 \text { to } 20) \\
\end{array}$ & $\begin{array}{c}28 \\
\text { (19 to } 35)\end{array}$ & $\begin{array}{c}9 \\
(-5 \text { to } 22) \\
\end{array}$ \\
\hline & $2014 / 15$ & $\begin{array}{c}23 \\
(-5 \text { to } 43)\end{array}$ & $\begin{array}{c}47 \\
\text { (21 to } 65)\end{array}$ & $\begin{array}{c}16 \\
\text { (-46 to } 52) \\
\end{array}$ & $\begin{array}{c}14 \\
\text { (8 to } 20 \text { ) }\end{array}$ & $\begin{array}{c}30 \\
\text { (23 to } 36)\end{array}$ & $\begin{array}{c}13 \\
\text { (2 to } 22 \text { ) }\end{array}$ \\
\hline & Pooled & $\begin{array}{c}17 \\
(-3 \text { to } 37)\end{array}$ & $\begin{array}{c}42 \\
\text { (24 to } 59)\end{array}$ & $\begin{array}{c}13 \\
(-22 \text { to } 48) \\
\end{array}$ & $\begin{array}{c}13 \\
\text { (7 to } 18)\end{array}$ & $\begin{array}{c}27 \\
\text { (23 to } 32)\end{array}$ & $\begin{array}{c}11 \\
\text { (3 to 19) }\end{array}$ \\
\hline \multirow{4}{*}{$\begin{array}{l}\text { Excluding subjects with greater than } 5 \% \\
\text { predicted mortality }\end{array}$} & $2012 / 13$ & $\begin{array}{c}-1 \\
(-60 \text { to } 36)\end{array}$ & $\begin{array}{c}22 \\
(-79 \text { to } 73)\end{array}$ & $\begin{array}{c}-5 \\
(-696 \text { to } \\
86) \\
\end{array}$ & $\begin{array}{c}-4 \\
(-130 \text { to } 53)\end{array}$ & $\begin{array}{c}24 \\
(-18 \text { to } 51)\end{array}$ & $\begin{array}{c}-3 \\
(-34 \text { to } 21)\end{array}$ \\
\hline & $2013 / 14$ & $\begin{array}{c}-2 \\
(-124 \text { to } 53)\end{array}$ & $\begin{array}{c}37 \\
(-9 \text { to } 64)\end{array}$ & $\begin{array}{c}1 \\
(-119 \text { to } \\
55)\end{array}$ & $\begin{array}{c}2 \\
(-30 \text { to } 26)\end{array}$ & $\begin{array}{c}21 \\
\text { (4 to } 35 \text { ) }\end{array}$ & $\begin{array}{c}0 \\
(-28 \text { to } 22)\end{array}$ \\
\hline & $2014 / 15$ & $\begin{array}{c}6 \\
(-165 \text { to } 67)\end{array}$ & $\begin{array}{c}41 \\
\text { (9 to } 55 \text { ) }\end{array}$ & $\begin{array}{c}-8 \\
(-389 \text { to } \\
76)\end{array}$ & $\begin{array}{c}8 \\
(-18 \text { to } 28)\end{array}$ & $\begin{array}{c}31 \\
\text { (19 to } 41 \text { ) }\end{array}$ & $\begin{array}{c}7 \\
(-13 \text { to } 24)\end{array}$ \\
\hline & Pooled & $\begin{array}{c}1 \\
(-44 \text { to } 46)\end{array}$ & $\begin{array}{c}36 \\
\text { (10 to } 62)\end{array}$ & $\begin{array}{c}-4 \\
(-98 \text { to } 89)\end{array}$ & $\begin{array}{c}2 \\
(-28 \text { to } 32)\end{array}$ & $\begin{array}{c}25 \\
\text { (12 to } 38)\end{array}$ & $\begin{array}{c}1 \\
(-12 \text { to } 15)\end{array}$ \\
\hline
\end{tabular}

$\mathrm{Cl}$ : confidence interval; rVE: relative vaccine effectiveness.

mortality (Supplementary Table 1), which impacted the estimate of rVE. Before this exclusion, the average 1-year predicted mortality for HD and SD recipients was $3.3 \%$ and $4.2 \%$, respectively, with a not statistically significant SMD of 9 . This suggests a successful balance by matching of this surrogate measure of frailty. Nevertheless, the exclusion approach appeared to have a larger impact than matching, which could suggest that HD conferred better protection relative to SD for the frailest veterans. Finally, it was reassuring that almost no residual confounding was observed during the non-influenza circulation period (summer) against all-cause hospitalisations.

The relative effectiveness between $\mathrm{HD}$ and SD was estimated during three seasons with varying circulating strains and vaccine efficacy. While influenza $A\left(\mathrm{H}_{3} \mathrm{~N}_{2}\right)$ viruses predominated in both the 2012/13 [28] and 2014/15 [29] seasons, 2013/14 [30] was the first influenza $A\left(\mathrm{H}_{1} \mathrm{~N}_{1}\right)$ pdmo9-predominant season since 2009. Nevertheless, VE were similar for both the $2012 / 13$ (49\%; $95 \mathrm{Cl}$ : 43-55) and 2013/14 season (52\%; $95 \mathrm{Cl}$ : 44-59) but dramatically lower for the $2014 / 15$ season, at an overall effectiveness of $19 \%$ (95 Cl: 10-27) [31]. The combination of low VE and predominant influenza $\mathrm{A}\left(\mathrm{H}_{3} \mathrm{~N}_{2}\right)$ viruses, which are associated with higher rates of influenza-associated hospitalisations among the elderly, may have contributed to the highest recorded rate of laboratory-confirmed, influenza-associated hospitalisations in the US, at 319.2 per 100,000 population in the $2014 / 15$ season. This rate exceeded the previously highest record of 183.2 per 100,000 for the $2012 / 13$ season by $74 \%$ [29]. Given the varying $\mathrm{rVE}, \mathrm{VE}$ and circulating viruses, it would be interesting to examine the association among the three. Unfortunately, including these variables in the model would add greater complexity and require additional seasons and data. Moreover, some veterans' vaccinations were not recorded in the VHA or CMS databases, resulting in incomplete vaccination data. We believe this incompleteness, and resulting misclassification, could have had a substantial impact on the estimation of VE. To evaluate the VE of each vaccine or to study the impact of repeated vaccinations would also require significant undertaking to avoid misclassifying those without vaccination records as being not vaccinated. To convey clear public health messages, we believe these should be studied carefully in the future. 
Relative vaccine effectiveness of high-dose vs standard dose influenza vaccination and mortality during high influenza period, matched and adjusted using two-stage residual inclusion model, among predominantly male, white, senior veterans, United States, 2012/13-2014/15 ( $\mathrm{n}=569,552)$

\begin{tabular}{|l|c|c|c|}
\multirow{2}{*}{ Season } & Influenza/pneumonia cause of death & Cardiorespiratory cause of death & $\begin{array}{c}\text { All-cause hospitalisations } \\
\text { (baseline) }\end{array}$ \\
\cline { 2 - 4 } & rVE \% $(95 \% \mathrm{Cl})$ & rVE \% (95\% Cl) & rVE \% $(95 \% \mathrm{Cl})$ \\
\hline $2012 / 13$ & $29(21$ to 36$)$ & $26(2$ to 44$)$ & $-7(-21$ to 5$)$ \\
\hline $2013 / 14$ & $11(-1$ to 22$)$ & $29(27$ to 30$)$ & $5(2$ to 8$)$ \\
\hline $2014 / 15$ & $21(11$ to 30$)$ & $31(30$ to 32$)$ & $-1(-5$ to 2$)$ \\
\hline Pooled & $23(17$ to 28$)$ & $30(23$ to 38$)$ & \\
\hline
\end{tabular}

$\mathrm{Cl}$ : confidence interval; rVE: relative vaccine effectiveness.

Our comparative effectiveness analysis of HD and $\mathrm{SD}$ vaccination on mortality explores the same question over the same period as Shay et al.'s analysis, but with differences in study populations, healthcare providers, outcome definitions and statistical methods. Nevertheless, our results were consistent with their overall rVE: $24 \%$ ( $95 \% \mathrm{Cl}: 6-42$ ) in post-influenza deaths, defined as " a death occurring in the 30 days following a Medicare claim for an inpatient hospitalisation or an emergency department visit with a diagnosis of influenza." [12] Clinical trial data have shown that the VE of HD might be greater for $A\left(\mathrm{H}_{3} \mathrm{~N}_{2}\right)$ than for $A\left(H_{1} N_{1}\right)$ influenza viruses [9]. This could explain some variation by season in our study, as our rVE were $29 \%$ (95\% Cl: 21-36) for 2012/13 (predominantly $A\left(\mathrm{H}_{3} \mathrm{~N}_{2}\right)$ ), $11 \%$ (95\% Cl: -1 to 22 ) for $2013 / 14$ (predominantly $\mathrm{A}\left(\mathrm{H}_{1} \mathrm{~N}_{1}\right)$ pdmog) and 21\% (95\% Cl: 11-30) for 2014/15 season (predominantly $\mathrm{A}\left(\mathrm{H}_{3} \mathrm{~N}_{2}\right)$ ). The pattern was similar, although less drastic than observed by Shay et al.: $36.4 \%(95 \% \mathrm{Cl}: 9.0-56)$ for $2012 / 13$ and $2.5 \%$ ( $95 \% \mathrm{Cl}:-47$ to 35 ) for $2013 / 14$ season. We focused on the high influenza period while Shay et al. analysed vaccinations that occurred mostly in what we categorised as the early and high influenza periods. However, they defined the period by the proportion of positive test $\mathbf{2} 75_{\text {th }}$ percentile for each region/season, which is similar to the $10 \%$ positive test rate that we used. Shay et al's primary method of adjusting for potential confounding, in addition to restricting participation to beneficiaries who were vaccinated in pharmacies, was multivariable adjustment, but they did not conduct matching or additional statistical modelling.

\section{Strengths}

The appropriate analysis and estimation of rVE depends on the correct adjustment for confounding by indication where some of the confounders are unmeasured. In our studies, we attempted three different approaches: (i) the previous event rate ratio method, a type of difference-in-differences analysis [14], (ii) the instrumental variable method, an econometric technique [15] and (iii) the current approach where findings of a vaccine effect during early and late influenza periods could indicate the presence of residual confounding after matching and multivariable analysis. Each approach has strengths and weaknesses that could be amplified or ameliorated with specific study populations, databases or influenza seasons examined. In this study, we experimented with different methods (e.g. two-stage residual inclusion estimation model) and cut-offs (e.g. high 1-year mortality risk) that sometimes resulted in divergent point estimates or wide $\mathrm{Cl}$, which could be due to varying sample sizes and statistical assumptions. As we continue to improve on our approaches, we hope that a pattern will emerge from this body of work that could contribute to the scientific inquiry of the rVE of HD and SD.

Moreover, we analysed more than half a million vaccinations and almost 10 thousand deaths. The large sample allowed us to adjust for more confounding variables without compromising statistical power, although not calculated beforehand. We combined data from VHA EMR records and Medicare administrative claims to compile a complete picture of healthcare encounters experienced by our study population. We studied both influenza/pneumonia and cardiorespiratory mortality, using the CDC's gold standard causes-of-death data [32]. We matched on the location and time of vaccination to better account for temporal and geographical factors associated with influenza disease movement. In addition, we matched on age group, sex, ethnicity and VHA priority rating. This comprehensive matching has been shown to improve the accuracy of estimation, although we would have constructed finer age groups if we had a larger sample size [33].

\section{Limitations}

The CDC's causes-of-death data lacks standardisation [32]. Since influenza and pneumonia are comparatively rare as causes of death, their designation might be more subjective especially during periods of low influenza activity. Thus, under-diagnosing could lead to variation in assignments of underlying cause of death. The VHA has a unique population: it is more than $90 \%$ male, predominantly white, and tends to have greater disease burden than the general US population, thus our finding is not generalisable [34]. Despite combining EMR records from the VHA and administrative claims from Medicare, a small amount of data might still be missing for those enrolled in Medicare Advantage (MA) plans. The proportion that enrolled in MA after vaccination 
was small (2.5\%), and since the most important data to the study were their vaccination status (HD vS SD), mortality outcome and baseline characteristics, the amount of missing data was negligible in the context of our study. Ninety-nine per cent of the vaccines we studied were egg-based with a 1:2 ratio between trivalent HD and trivalent SD in our matched samples. Twothirds of the trivalent SD were supplied by the same company. Although rVE might differ depending on the specific types of SD (e.g. cell-based, adjuvanted, etc.), we did not have the needed sample size to study the impact of different vaccine types. Additional data on morbidities such as obesity could also have improved measurement on confounding. Finally, VE and rVE are likely to be impacted by the season-dependent match between the vaccine and the predominant circulating strain, as well as by the severity of the influenza season [13].

\section{Conclusion}

Using a combination of approaches, we estimated rVE and mortality in a predominantly male, white, senior VHA patient population. We found that HD was associated with a lower risk of influenza/pneumonia-associated and cardiorespiratory mortality during the high influenza period, an effect that could vary by season.

\section{Acknowledgements}

Dr. Mahmud is a Canada Research Chair in
Pharmacoepidemiology and Vaccine Evaluation.

Funding: This work was supported by an unrestricted research grant from Sanofi Pasteur where the funder did not have any influence over study design or interpretation of the results, a condition without which that VA IRB would not have granted approval.

\section{Conflict of interest}

YYX has received research funding from Sanofi Pasteur, Pfizer, Genentech, Janssen, Vir Biotechnology, and the Office of Rural Health Resource Center-Eastern Region. EMR received research funding from Sanofi Pasteur. JTS is an employee and holds equity in Precision Health Economics, which provides consulting services to the life sciences industry. SMM has received research funding from Assurex, GSK, Merck, Pfizer, Roche and Sanofi, and is/was a member of advisory boards for GSK and Sanofi. RVA, JKL, EWT and AC are employees of Sanofi Pasteur.

\section{Authors' contributions}

Study conceptualisation: YYX, JTS, SMM, RVA, EWT, JKL, AC; Literature research: YYX, EMR, JKL; Data collection: YYX, EMR; Data analysis code: YYX; Data Analysis: YYX; Results interpretation: YYX, JTS, SMM, RVA, EWT, JKL, AC; Manuscript writing: YYX, JTS, SMM, EMR, RVA, EWT, JKL, AC; Manuscript review: YYX, JTS, SMM, EMR, RVA, EWT, JKL, AC; Coordination: YYX.

\section{References}

1. Young-Xu Y, van Aalst R, Russo E, Lee JK, Chit A. The annual burden of seasonal influenza in the US veterans affairs population. PLoS One. 2017;12(1):e0169344. https://doi. org/10.1371/journal.pone.0169344 PMID: 28046080

2. Centers for Disease Control and Prevention. Prevention and control of seasonal influenza with vaccines. Recommendations of the Advisory Committee on Immunization Practices--United States, 2013-2014. MMWR Recomm Rep. 2013;62(RR-07):1-43. PMID: 24048214

3. Thompson WW, Shay DK, Weintraub E, Brammer L, Bridges CB, Cox NJ, et al. Influenza-associated hospitalizations in the United States. JAMA. 2004;292(11):1333-40. https://doi. org/10.1001/jama.292.11.1333 PMID: 15367555

4. Thompson WW, Shay DK, Weintraub E, Brammer L, Cox $\mathrm{N}$, Anderson LJ, et al. Mortality associated with influenza and respiratory syncytial virus in the United States. JAMA. 2003;289(2):179-86. https://doi.org/10.1001/jama.289.2.179 PMID: 12517228

5. Thompson WW, Moore MR, Weintraub E, Cheng PY, Jin X, Bridges CB, et al. Estimating influenza-associated deaths in the United States. Am J Public Health. 2009;99(S2) Suppl 2;S225-30. https://doi.org/10.2105/AJPH.2008.151944 PMID: 19797736

6. Monto AS, Ansaldi F, Aspinall R, McElhaney JE, Montaño LF, Nichol KL, et al. Influenza control in the 21st century: Optimizing protection of older adults. Vaccine. 2009;27(37):5043-53. https://doi.org/10.1016/j. vaccine.2009.06.032 PMID: 19559118

7. DiazGranados CA, Dunning AJ, Jordanov E, Landolfi V, Denis M, Talbot HK. High-dose trivalent influenza vaccine compared to standard dose vaccine in elderly adults: safety, immunogenicity and relative efficacy during the 2009-2010 season. Vaccine. 2013;31(6):861-6. https://doi.org/10.1016/j. vaccine.2012.12.013 PMID: 23261045

8. Gravenstein S, Davidson HE, Taljaard M, Ogarek J, Gozalo P, Han L, et al. Comparative effectiveness of high-dose versus standard-dose influenza vaccination on numbers of US nursing home residents admitted to hospital: a cluster-randomised trial. Lancet Respir Med. 2017;5(9):738-46. https://doi. org/10.1016/S2213-2600(17)30235-7 PMID: 28736045

9. DiazGranados CA, Dunning AJ, Kimmel M, Kirby D, Treanor J, Collins A, et al. Efficacy of high-dose versus standarddose influenza vaccine in older adults. N Engl J Med. 2014;371(7):635-45. https://doi.org/10.1056/NEJMoa1315727 PMID: 25119609

10. DiazGranados CA, Robertson CA, Talbot HK, Landolfi V, Dunning AJ, Greenberg DP. Prevention of serious events in adults 65 years of age or older: A comparison between high-dose and standard-dose inactivated influenza vaccines. Vaccine. 2015;33(38):4988-93. https://doi.org/10.1016/j. vaccine.2015.07.006 PMID: 26212007

11. Richardson DM, Medvedeva EL, Roberts CB, Linkin DRCenters for Disease Control and Prevention Epicenter Program. Comparative effectiveness of high-dose versus standard-dose influenza vaccination in community-dwelling veterans. Clin Infect Dis. 2015;61(2):171-6. https://doi.org/10.1093/cid/civ261 PMID: 25829001

12. Izurieta HS, Thadani N, Shay DK, Lu Y, Maurer A, Foppa IM, et al. Comparative effectiveness of high-dose versus standarddose influenza vaccines in US residents aged 65 years and older from 2012 to 2013 using Medicare data: a retrospective cohort analysis. Lancet Infect Dis. 2015;15(3):293-300. https:// doi.org/10.1016/S1473-3099(14)71087-4 PMID: 25672568

13. Shay DK, Chillarige Y, Kelman J, Forshee RA, Foppa IM, Wernecke $M$, et al. Comparative effectiveness of high-dose versus standard-dose influenza vaccines among US Medicare beneficiaries in preventing postinfluenza deaths during 2012 2013 and 2013-2014. J Infect Dis. 2017;215(4):510-7. https:// doi.org/10.1093/infdis/jiw641 PMID: 28329311

14. Young-Xu Y, Van Aalst R, Mahmud SM, Rothman KJ, Snider JT, Westreich D, et al. Relative vaccine effectiveness of high-dose versus standard-dose influenza vaccines among veterans health administration patients. J Infect Dis. 2018;217(11):171827. https://doi.org/10.1093/infdis/jiyo88 PMID: 29452380

15. Young-Xu Y, Snider JT, van Aalst R, Mahmud SM, Thommes EW, Lee JKH, et al. Analysis of relative effectiveness of high-dose versus standard-dose influenza vaccines using an instrumental variable method. Vaccine. 2019;37(11):1484-90. https://doi. org/10.1016/j.vaccine.2019.01.063 PMID: 30745146

16. National Center for Health Statistics. National Death Index user's guide. Hyattsville: Centers for Disease Control and Prevention. 2013. Available from: https://www.cdc.gov/nchs/ data/ndi/NDI_Users_Guide.pdf

17. International Classification of Diseases. Tenth Revision (ICD10). Atlanta; CDC. [Accessed: 9 May 2020]. Available from: https://www.cdc.gov/nchs/icd/icd10.htm 
18. Centers for Disease Control and Prevention (CDC). U.S. Influenza Surveillance System: Purpose and Methods. Atlanta; CDC.[Accessed: 7 Jul 2018]. Available from: http://www.cdc. gov/flu/weekly/overview.htm

19. Campitelli MA, Rosella LC, Stukel TA, Kwong JC. Influenza vaccination and all-cause mortality in communitydwelling elderly in Ontario, Canada, a cohort study. Vaccine. 2010;29(2):240-6. https://doi.org/10.1016/j. vaccine.2010.10.049 PMID: 21044667

20. Petersen LA, Byrne MM, Daw CN, Hasche J, Reis B, Pietz K. Relationship between clinical conditions and use of Veterans Affairs health care among Medicare-enrolled veterans. Health Serv Res. 2010;45(3):762-91. https://doi.org/10.1111/j.14756773.2010.01107.x PMID: 20403056

21. Deyo RA, Cherkin DC, Ciol MA. Adapting a clinical comorbidity index for use with ICD-9-CM administrative databases. J Clin Epidemiol. 1992;45(6):613-9. https://doi.org/10.1016/08954356(92)90133-8 PMID: 1607900

22. Elixhauser A, Steiner C, Harris DR, Coffey RM. Comorbidity measures for use with administrative data. Med Care. 1998;36(1):8-27. https://doi.org/10.1097/00005650199801000-00004 PMID: 9431328

23. Wang L, Porter B, Maynard C, Evans G, Bryson C, Sun H, et al. Predicting risk of hospitalization or death among patients receiving primary care in the Veterans Health Administration. Med Care. 2013;51(4):368-73. https://doi.org/10.1097/ MLR.obo13e31827da95a PMID: 23269113

24. Austin PC, Stuart EA. Moving towards best practice when using inverse probability of treatment weighting (IPTW) using the propensity score to estimate causal treatment effects in observational studies. Stat Med. 2015;34(28):3661-79. https:// doi.org/10.1002/sim.6607 PMID: 26238958

25. Fiore $A E$, Bridges CB, Katz JM, Cox NJ. Inactivated influenza vaccines. In: Vaccines. 6th ed. Philadelphia: Elsevier Inc. 2012:257-92.

26. Heckman JJ, Robb R Jr. Alternative methods for evaluating the impact of interventions: An overview. J Econom. 1985;30(12):239-67. https://doi.org/10.1016/0304-4076(85)90139-3

27. Simonsen L, Taylor RJ, Viboud C, Miller MA, Jackson LA. Mortality benefits of influenza vaccination in elderly people: an ongoing controversy. Lancet Infect Dis. 2007;7(10):658 66. https://doi.org/10.1016/S1473-3099(07)70236-0 PMID: 17897608

28. Centers for Disease Control and Prevention (CDC). Influenza activity--United States, 2012-13 season and composition of the 2013-14 influenza vaccine. MMWR Morb Mortal Wkly Rep. 2013;62(23):473-9. PMID: 23760189

29. Appiah GD, Blanton L, D'Mello T, Kniss K, Smith S, Mustaquim $D$, et al. Centers for Disease Control and Prevention (CDC). Influenza activity - United States, 2014-15 season and composition of the 2015-16 influenza vaccine. MMWR Morb Mortal Wkly Rep. 2015;64(21):583-90. PMID: 26042650

30. Epperson S, Blanton L, Kniss K, Mustaquim D, Steffens C, Wallis T, et al. Influenza Division, National Center for Immunization and Respiratory Diseases, CDC. Influenza activity - United States, 2013-14 season and composition of the 2014-15 influenza vaccines. MMWR Morb Mortal Wkly Rep. 2014;63(22):483-90. PMID: 24898165

31. Centers for Disease Control and Prevention (CDC). Influenza (flu): Past seasons vaccine effectiveness estimates. Atlanta: CDC. [Accessed: 28 Oct 2019]. Available from: https://www. cdc.gov/flu/vaccines-work/past-seasons-estimates.html

32. Olubowale OT, Safford MM, Brown TM, Durant RW, Howard VJ, Gamboa C, et al. Comparison of expert adjudicated coronary heart disease and cardiovascular disease mortality with the national death index: results from the Reasons for Geographic and Racial Differences in Stroke (REGARDS) Study. J Am Heart Assoc. 2017;6(5):e004966. https://doi.org/10.1161/ JAHA.116.004966 PMID: 28468785

33. Robison SG, Thomas AR. Assessing the effectiveness of highdose influenza vaccine in preventing hospitalization among seniors, and observations on the limitations of effectiveness study design. Vaccine. 2018;36(45):6683-7. https://doi. org/10.1016/j.vaccine.2018.09.050 PMID: 30287157

34. Rogers WH, Kazis LE, Miller DR, Skinner KM, Clark JA, Spiro A 3 rd, et al. Comparing the health status of VA and nonVA ambulatory patients: the veterans' health and medical outcomes studies. J Ambul Care Manage. 2004;27(3):249-62. https://doi.org/10.1097/00004479-200407000-00009 PMID: 15287215
This is an open-access article distributed under the terms of the Creative Commons Attribution (CC BY 4.0) Licence. You may share and adapt the material, but must give appropriate credit to the source, provide a link to the licence and indicate if changes were made.

Any supplementary material referenced in the article can be found in the online version.

This article is copyright of the authors or their affiliated institutions, 2020. 